\title{
Second International Conference on Biomedical Spectroscopy: From lab to clinic
}

5-8 July 2003, London, UK

The second international conference on Biomedical Spectroscopy will bring together spectroscopists and life scientists, from academia and industry, engaged in solving problems of biological and biomedical interest using diverse spectroscopic techniques.

The interdisciplinary nature of the conference will encourage scientific interchange and crossfertilisation of ideas.

Application of spectroscopic techniques such as

Mass spectrometry, FTIR, NMR, EPR, ENDOR, NIR, SPR, Raman, CD, EXAFS, UV/Visible, Atomic Force Spectroscopy, Neutron Spectroscopy, Dielectric, Spectroscopy, Fluorescence Spectroscopy and so on,

for solving problems in diverse areas of life science including

- Biomedical and Clinical Science,

- Biochemistry and Biophysics,

- Biomaterials and Biosensors,

- Proteomics and Pharmaceuticals,

- Biotechnology and Biomedical Engineering.

Scientists employing spectroscopic techniques in life science research are invited to submit proposals for lectures and poster presentations. Papers presented at the conference will be reviewed and published in a special issue of Spectroscopy. For submission of proposals and other information please contact:

Dr. Parvez I. Haris

Department of Biological Sciences

De Montfort University

Leicester, LE1 9BH

UK

E-mail: pharis@dmu.ac.uk 


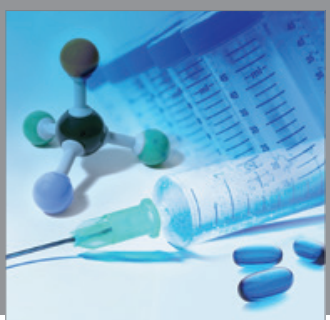

International Journal of

Medicinal Chemistry

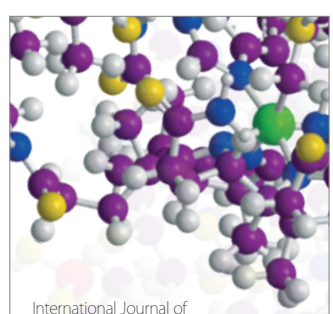

Carbohydrate Chemistry

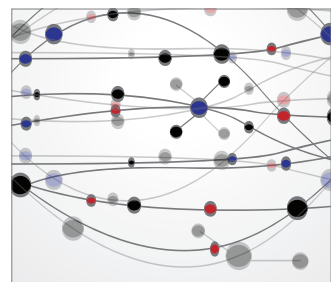

The Scientific World Journal
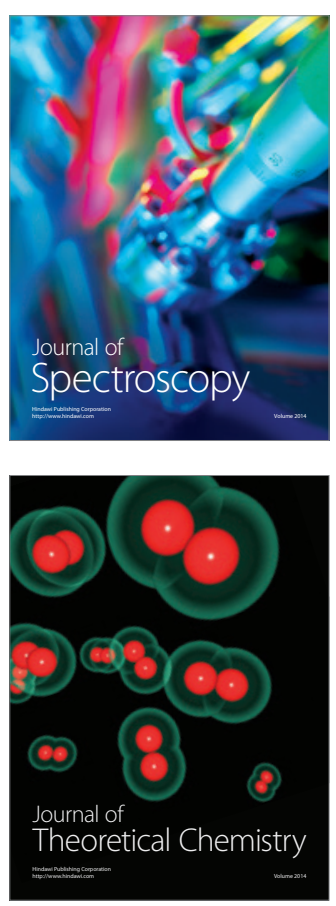
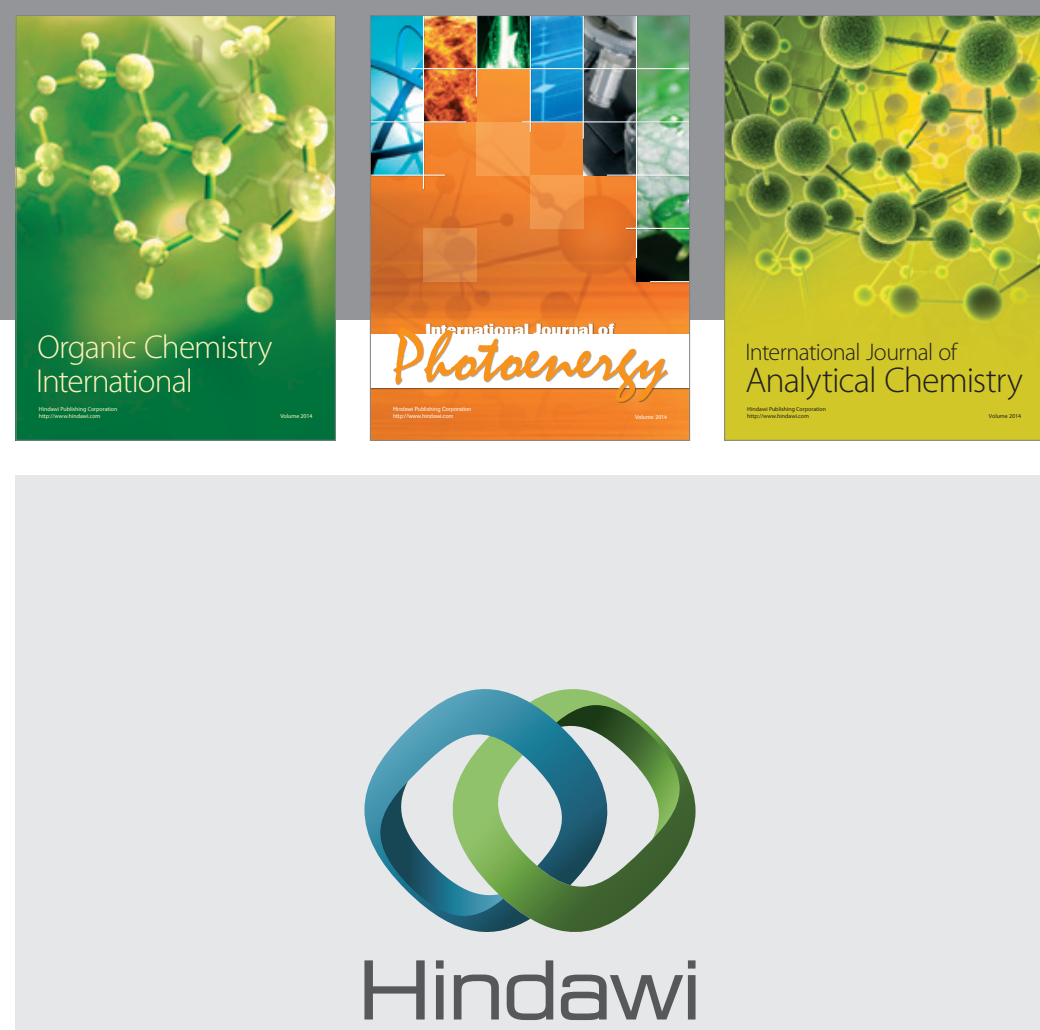

Submit your manuscripts at

http://www.hindawi.com
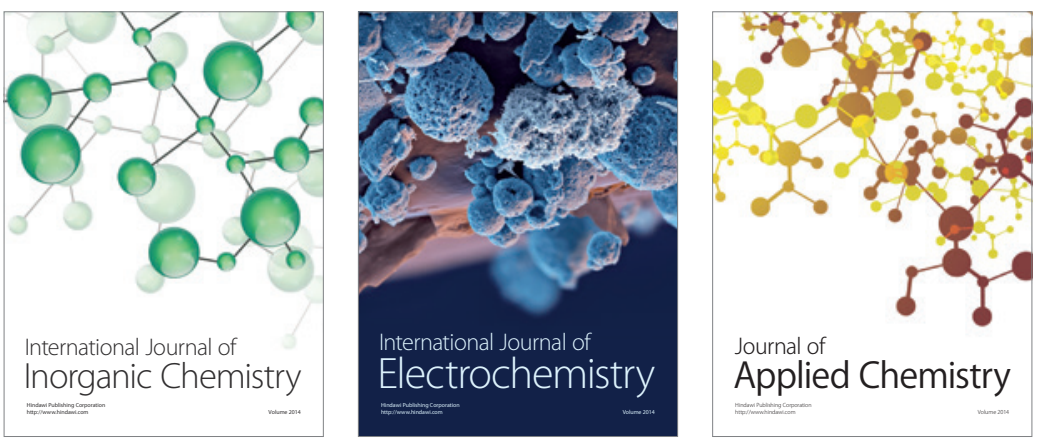

Journal of

Applied Chemistry
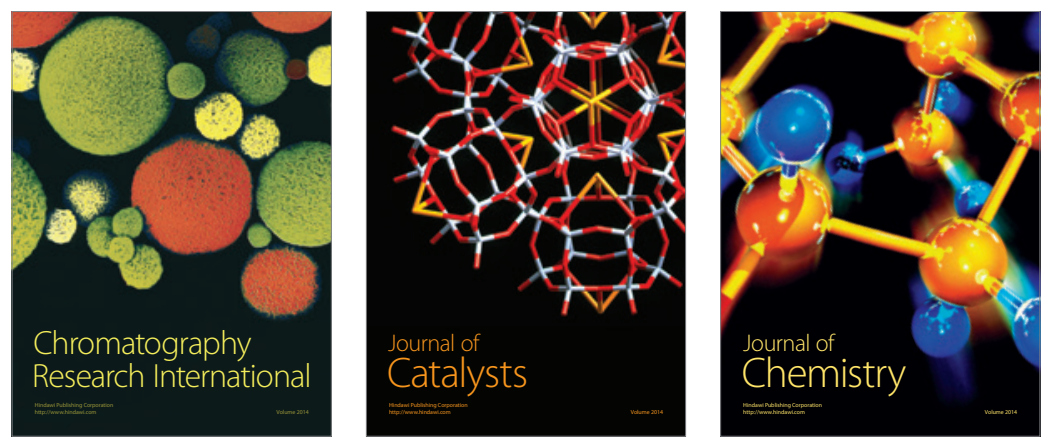
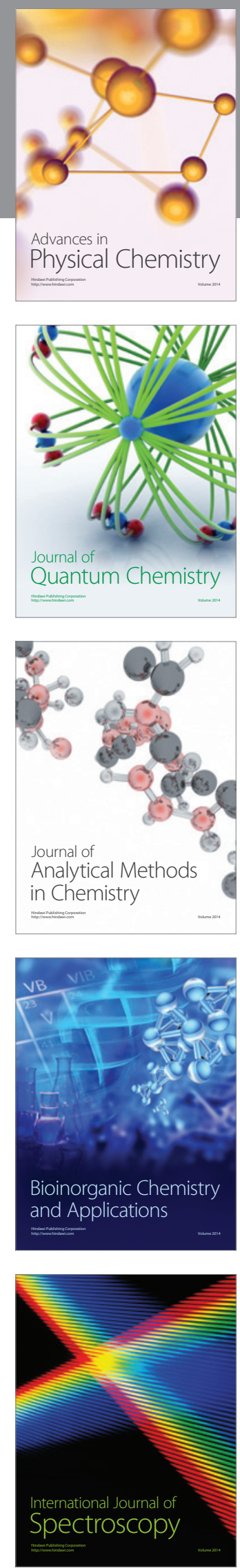